\title{
Configurações
}

Revista de sociologia

\section{A educação de pares em contexto prisional: representações de reclusos acerca do seu potencial de capacitação e empoderamento}

Peer education in the prison context: representations of prisoners in terms of their empowerment potential

L'éducation de pairs en prison: représentations de reclus à propos de leur potentiel de capacitation et émancipation

Andreia Nisa, Diana Castro, Telma Passos e Helena M. Carvalho

\section{OpenEdition}

\section{Journals}

Edição electrónica

URL: http://journals.openedition.org/configuracoes/5028

DOI: $10.4000 /$ configuracoes.5028

ISSN: 2182-7419

Editora

Centro de Investigação em Ciências Sociais

Edição impressa

Paginação: 10-27

ISSN: 1646-5075

\section{Refêrencia eletrónica}

Andreia Nisa, Diana Castro, Telma Passos e Helena M. Carvalho, « A educação de pares em contexto prisional: representações de reclusos acerca do seu potencial de capacitação e empoderamento », Configurações [Online], 21 | 2018, posto online no dia 30 junho 2018, consultado o 01 maio 2019. URL : http://journals.openedition.org/configuracoes/5028; DOI : 10.4000/configuracoes.5028 
Nisa, Andreia; Castro, Diana; Passos, Telma; Carvalho, Helena Moura - A educação de pares em contexto prisional: representações de reclusos acerca do seu potencial de capacitação e empoderamento. Configurações, vol. 21, 2018, pp. 10-27.

\title{
A educação de pares em contexto prisional: representações de reclusos acerca do seu potencial de capacitação e empoderamento
}

\author{
ANDREIA NISA* \\ Agência Piaget para o Desenvolvimento (APDES) / Research in Education and Community Intervention (RECI) \\ DIANA CASTRO** \\ Agência Piaget para o Desenvolvimento (APDES) \\ TELMA PASSOS*** \\ Agência Piaget para o Desenvolvimento (APDES) \\ HELENA MOURA CARVALHO**** \\ Agência Piaget para o Desenvolvimento (APDES) / Research in Education and Community Intervention (RECI)
}

\begin{abstract}
Resumo
A educação de pares é uma metodologia relevante na intervenção no contexto prisional. O objectivo do presente estudo é analisar as representações sobre as implicações desta metodologia na promoção do desenvolvimento pessoal e social de reclusos. Nesse sentido foram realizados 6 focus groups com 25 reclusos que beneficiaram da formação de educadores de pares implementada no âmbito do projecto Inclus@ no Estabelecimento Prisional da Guarda. Na análise emergiram 4 categorias: valorização do sentido de competência pessoal; reforço de competências sociais; aumento da capacidade de participação no espaço público e empoderamento do indivíduo. Os resultados serão discutidos problematizando o papel que a educação de pares pode ter no contexto prisional.
\end{abstract}

Palavras-chave: Educação Pares, prisão, empoderamento e desenvolvimento pessoal.

\footnotetext{
*E-mail: andreia.nisa@apdes.pt

**E-mail: diana.castro@apdes.pt

***E-mail: telma.passos@gmail.com

****E-mail: helena.moura@apdes.pt
} 


\begin{abstract}
Peer education in the prison context: Representations of prisoners in terms of their empowerment potential

Peer education is a relevant methodology for intervention in the prison context. The goal of this study is to analyse the representations about the implications of this methodology in the promotion of the personal and social development of prisoners. In this sense, 6 focus groups were carried out with 25 inmates who benefited from the training of peer educators implemented by project Inclus@ in the Prison of Guarda. 4 categories emerged in the analysis: valorisation of the sense of personal competence; strengthening of social skills; increase of the ability to participate in the public space and empowerment of the individual. The results will be discussed analysing the role that peer education can play in the prison context.
\end{abstract}

Keywords: Peer education, prison, empowerment and personal development.

\title{
Résumé
}

L'éducation de pairs en prison : Représentations de reclus à propos de leur potentiel de capacitation et émancipation

L'éducation par les pairs est une méthodologie pertinente dans l'intervention pénitentiaire. L'objectif de cette étude est d'analyser les représentations sur les implications de cette méthodologie dans la promotion du développement personnel et social des détenus. En ce sens, 6 focus groups ont été réalisés avec 25 détenus qui ont bénéficié de la formation de pairs éducateurs mise en place dans le cadre du projet Inclus@ dans l'établissement pénitentiaire de Guarda. 4 catégories ont émergé de l'analyse : la valorisation du sens de la compétence personnelle ; le renforcement des compétences sociales ; l'augmentation de la capacité de participation dans l'espace public et l'autonomisation de l'individu. Les résultats seront discutés avec la problématisation du rôle que l'éducation par les pairs peut avoir dans le contexte de la prison.

Mots-clés: Éducation, pairs, prison, émancipation et développement personnel.

\section{Introdução}

A continuing challenge in public bealth is to get services to the people who need them the most, especially those who are hardest to reach. Yet it is a sad reality of life that, at any one time, a high proportion of those with multiple health problems are incarcerated in the prisons of each country. They are certainly reachable, for a certain period at least. (World Health Organization - WHO, 2007a: vii)

A necessidade de intervenção em contexto prisional tem sido sublinhada por diversas entidades internacionais das Nações Unidas (e.g., WHO, 2007a; 2007b, 2014; United Nations Office on Drugs and Crime - UNODC, 2008, 
Joint United Nations Program on HIV/AIDS - UNAIDS, 2014), em particular através do Programa Conjunto das Nações Unidas sobre VIH/SIDA e mais recentemente, pela Estratégia Europeia das Drogas (2013-2020). Adicionalmente, a resposta à necessidade de prestação de cuidados de saúde relacionados com o consumo de substâncias psicoativas por parte da população reclusa é identificada ainda como uma prioridade de saúde pública pela União Europeia e pelos Estados-Membros (e.g., Plano Nacional para a Redução dos Comportamentos Aditivos e das Dependências 2013-2020, Estratégia Europeia das Drogas 2013-2020). Prioridade já anteriormente intencionalizada no Plano de Acção da União Europeia em matéria de luta contra a droga (2009-2012) e na Declaração de Dublin sobre as Parcerias para combater o VIH/Sida na Europa e na Ásia Central (European Monitoring Centre for Drugs and Drug Addiction - EMCDDA, 2012). A população reclusa é uma população particularmente vulnerável nomeadamente no que se refere à prevalência de doenças infectocontagiosas, sendo que a prevalência de VIH, Hepatite B e C, tuberculose é cerca de duas a dez vezes maior do que na população em geral (UNAIDS, 2014).

Os utilizadores de substâncias psicoativas continuam a representar uma percentagem significativa da população reclusa da Europa, com vários estudos a revelarem que a maioria dos reclusos em algum momento da sua vida já consumiram substâncias psicoativas ilícitas e muitos apresentam padrões de consumo problemático (EMCDDA, 2012). Adicionalmente, os reclusos parecem estar particularmente vulneráveis à doença mental e estigma, apresentando taxas de suicídio mais elevadas quando comparadas com as da população em geral da mesma idade (e.g., Barry, 2010; Fazel e Danesh, 2002; Nisa et. al. 2016). O cluster de determinantes de risco parece concorrer ainda para explicar uma esperança média de vida menor (Barry, 2010).

Apesar da pluricausalidade do comportamento criminal (Gomes e Silva, 2014) existem variáveis de carácter social e económico que parecem vulnerabilizar trajetórias de marginalização e de consequente reclusão (e.g., Dumont, 2012). Holmes (2002) descreve o impacto da pobreza, na determinação das trajetórias de vida nos Estados Unidos da América, sublinhando o seu poder explicativo numa panóplia de indicadores de desenvolvimento como o sendo o acesso mais condicionado à saúde e à educação e um número mais elevado de taxas de reclusão e de penas mais pesadas nomeadamente em penas de morte.

Adicionalmente, a prioridade de intervenção no contexto prisional ultrapassa as fronteiras do espaço de reclusão e inscreve-se no espectro mais alargado da comunidade. Todos os anos cerca de 30 milhões de pessoas encontram-se em situação de reclusão ou em sistemas fechados, sendo que 10 milhões de pessoas são a dado momento na sua vida encarceradas. Em determinada altura estes indivíduos irão retornar à sua comunidade sendo que a saúde nas prisões está diretamente associada à saúde na população em geral (UNAIDS, 2014: 5). 


\section{A Prisão em Portugal: Estabelecimento Prisional da Guarda (EPG)}

Portugal apresenta uma elevada taxa de ocupação dos estabelecimentos prisionais, apresentando-se em situação de sobrelotação. Em 31 de Dezembro de 2016 a população prisional total era de 13.779 reclusos/as. O número de preventivos era de $2.117(15,3 \%)$ e o de condenados de 11.662 (84,7\%). Quanto ao género, 93,7\% eram homens e $6,3 \%$ mulheres. Esta população tem um rácio por 100 mil habitantes (133), superior ao de países como a Áustria, a Alemanha, a França, a Bélgica, a Grécia, a Irlanda e a Itália (RASI, 2016: 133). No que toca à tipologia dos crimes cometidos, continuam a predominar os crimes contra o património $(27,7 \%)$, seguidos dos crimes contra as pessoas (24,9\%) e relativos a estupefacientes (18,9\%) (RASI, 2016: 133).

Apesar de se verificar uma tendência de decréscimo no número de reclusos diretamente em cumprimento de pena por crimes relacionados com o tráfico de droga, estes representavam ainda, em 2016, 18,9\% da população reclusa, sendo que que $27,7 \%$ dos crimes contra o património estão indiretamente relacionados com o consumo/tráfico de droga. Dados do Inquérito Nacional sobre Comportamentos Aditivos em Meio Prisional (INCAMP, 2014) indicam que $41,7 \%$ dos inquiridos afirma ter estado sob o efeito de drogas e $27,7 \%$ sob o efeito de bebidas alcoólicas quando cometeram os crimes que motivaram a atual reclusão (Torres, 2016). Outros factores, como o nível de instrução, revelam igualmente uma tendência homogeneizadora da população de reclusos nos estabelecimentos prisionais portugueses. Esta população caracteriza-se por apresentar um reduzido nível de escolaridade. Consequentemente a pouca qualificação escolar, pode traduzir-se em profissões de baixa remuneração, pouco satisfatórias tanto a nível social como económico, e dar origem, associada a outros fatores, a trajetórias de vida mais vulneráveis ao desenvolvimento de comportamentos de risco que conduzem às dependências, à delinquência e ao crime e posterior reclusão (Torres, 2016).

No que se refere ao EPG, os dados são concordantes com os revelados nos restantes estabelecimentos prisionais, sendo que a maioria das condenações estão associadas a crimes de tráfico (25\%) (CRI da Guarda, 2017). Dados do Centro de Respostas Integradas (CRI) da Guarda revelam ainda que no decorrer de 2016, 61 reclusos mantiveram um acompanhamento regular dos serviços, e 17 reclusos beneficiaram de programas de substituição opiácea com metadona. Em relação ao consumo de álcool, verifica-se um consumo pouco expressivo dentro do EPG, no entanto o número de indivíduos que em contexto de não reclusão apresentam consumos abusivo de álcool é bastante acentuado (CRI da Guarda, 2017).

\section{1. Intervir na Prisão}

Além das especificidades inerentes à população reclusa, o contexto prisional representa ainda um desafio no que se refere à intervenção. Note-se que o 
contexto prisional é um espaço fechado, recortado, vigiado em todos os seus pontos, onde os indivíduos estão inseridos num lugar físico, os seus movimentos são controlados e todos os acontecimentos são registados (Foucault, 1999). Todas as atividades diárias são rigorosamente estabelecidas em horários e toda a sua sequência é hetero-imposta por um sistema de regras formais explícitas. No contexto prisional toda a atividade quotidiana do indivíduo é submetida a uma regulamentação, estritamente programada e planificada (Carvalho, 2003). De facto, a prisão tem sempre associada uma ideia de força, segurança e de legitimidade de privação da liberdade da pessoa que condiciona a intervenção. Contudo, o sistema prisional tem vindo a sofrer transformações consideráveis, nomeadamente na forma como compreende a sua função social, procurando-se que o tempo de reclusão constitua também uma oportunidade de desenvolvimento da pessoa (Cunha, 2013). Tal mudança actualiza-se na aproximação cada vez maior da sociedade civil ao meio prisional e na implementação de novas formas de intervir no contexto prisional mais focadas na pessoa e no seu desenvolvimento integral. Assim, as intervenções em contexto prisional têm vindo a privilegiar uma abordagem integrada e psicossocial das problemáticas da pessoa em reclusão, sendo a educação de pares progressivamente reconhecida como uma metodologia privilegiada de intervenção em contexto prisional. A educação de pares pode ser implementada com diversas populações, através de um contacto individual ou em pequenos grupos e permite atingir indivíduos e/ou grupos dificilmente alcançáveis por estruturas formais já existentes (APDES, 2016). Com efeito, as intervenções dos educadores de pares, nas quais os reclusos disponibilizam informação, apoio e aconselhamento a outros reclusos podem contribuir para a concretização de políticas de saúde e sociais. A capacidade dos pares se relacionarem com outros reclusos e terem influência social em populações vulneráveis resistentes a aconselhamento profissional parece ter implicações directas para os próprios reclusos, educadores, mas também representa benefícios mais amplos para o sistema prisional, incluindo uma utilização eficaz dos recursos ampliando o leque de serviços de saúde no sistema prisional (Bagnall, 2015).

Nesse sentido, a articulação entre educadores de pares e técnicos revela-se uma prática cada vez mais disseminada em contexto internacional, verificando algumas excepções em contexto nacional com populações outreach, reforçando o seu carácter inovador na qualidade de intervenção disponibilizada nomeadamente no que se refere à dinamização do trabalho e tarefas da equipa, na sensibilização para os serviços, na identificação de novos territórios de intervenção e na adaptação de estratégias de intervenção (APDES, 2012). Adicionalmente, a inclusão de educadores de pares na elaboração, implementação e avaliação dos projetos é por si só um instrumento de empoderamento e de participação cívica, sendo sublinhada, a par de outros setores da sociedade civil, por 
agências internacionais no sentido de maximizar a intervenção em contextos outreach (e.g., Estratégia Europeia das Drogas, 2013-2020, Devilly, 2005).

\subsection{Educação de Pares no EPG}

O projecto INCLUS@ tem vindo a ser implementado no EPG pela APDES desde 2008, contando já com 4 edições agrupadas em 2 eixos de intervenção: prevenção e reinserção ${ }^{1}$. A educação de pares inscreve-se no eixo da prevenção e a sua implementação teve início em $2010^{2}$, após um período de avaliação de necessidades e de desenvolvimento de uma ação formativa adaptada ao EPG.

A primeira etapa da implementação da educação de pares corresponde à formação e visa promover o desenvolvimento de competências no grupo de formandos (pessoais, sociais e profissionais) indispensáveis para a ação do educador no contexto prisional. Os módulos formativos incluem a 1) promoção da saúde em contexto prisional; 2) prevenção do consumo de substâncias psicoativas (SPA's); 3) educação de pares e cidadania; 4) promoção do bem-estar físico e psicológico e 5) intervenção de pares em contexto prisional. A formação compreende ainda 4 etapas: 1) planeamento da formação em articulação com os profissionais e direção do EPG e pré-seleção dos formandos realizada em conjunto pela equipa técnica do EPG e a equipa técnica do Inclus@, sendo posteriormente sujeita a aprovação da Direção do EPG e da Chefia do Corpo de Guardas; 2) entrevistas individuais para seleção dos formandos, e melhor compreensão do seu interesse e motivação; 3) Formação propriamente dita e 4) Avaliação. A pré-seleção ${ }^{3}$ dos formandos é efetuada em conjunto pela equipa

1 O eixo da prevenção inclui 6 ações: 1) Formação em Educação de Pares para a Promoção da Saúde em Contexto Prisional, 2) Educação de Pares para a Promoção da Saúde em Contexto Prisional, 3) Dinâmicas \& Debates Entre Pares: Ações de Informação e Sensibilização, 4) Via Verde para a Saúde, 5) Atividades Lúdicas e Culturais, 6) Seminário Final. O eixo da reinserção inclui 4 ações que pressupõem uma implementação conjunta e articulada entre si por forma a desenhar para cada recluso uma intervenção individualizada: 1) Gabinete de Apoio Psicossocial; 2) Formação para a Empregabilidade; 3) Gabinete de Apoio ao Emprego; 4) Seminário.

2 Na terceira edição (2014-2016), e após os primeiros dois anos da formação, foi necessário proceder a algumas reformulações. O processo de revisão do desenho formativo teve por base a avaliação de processos e resultados formativos, nomeadamente no que se refere à revisão dos conteúdos de formação, referentes às competências transversais e que se reportam à função/perfil geral do EP (comunicação, perfil/função, RR, etc.), particularmente os que precisam de ser adaptados à especificidade do contexto; à introdução dos módulos "Prevenção da overdose" e "Prevenção do suicídio", temas de particular importância no contexto prisional; à ampliação da utilização de metodologias activas com vista à maximização da transferência de aprendizagens para contextos reais; e à diminuição do número de horas de formação por módulo, e correspondente duração total, de modo a permitir uma maior agilização da acção formativa, adaptando-a aos condicionalismos do contexto.

$3 \mathrm{O}$ processo de pré-selecção inclui a análise de competências relacionais como sendo o interesse pelo outro; empatia; abertura à mudança; capacidade para lidar com emoções e situações difíceis; respeito pelo outro, pelas decisões individuais e pela confidencialidade da informação; capacidade para trabalhar em rede e em equipa (APDES, 2016). Por outro lado, a par das competências pessoais e sociais, o Educador de Pares também deve adquirir um conjunto de competências técnicas, nomeadamente no que se refere a: conhecimentos sanitários, socio-legislativos e interculturais; doenças infecciosas, práticas de consumo e práticas sexuais de menor risco; princípios da prevenção e da redução de riscos; direitos dos cidadãos, entre outros. 
técnica do projeto e pelos técnicos do EPG, tendo em conta o perfil previamente desenhado e, dando ênfase àqueles que em termos de características jurídico-penais e percurso pessoal e prisional beneficiaram mais com esta formação. Nesta análise tem-se em consideração diversos aspectos privilegiando tanto características do educador de pares como dos futuros pares intervencionados e o contexto de intervenção. O processo de seleção culmina em entrevistas individuais onde são também apresentados os princípios da intervenção de Educação de Pares e as atividades a implementar.

Considerando a necessidade de produzir conhecimento científico neste domínio de forma a informar práticas ajustadas às reais necessidades da população reclusa, o projecto Inclus@ procurou avaliar a intervenção tendo em conta as narrativas dos educadores de pares que participaram nas 3 edições do projecto que incluiram a educação de pares. Assim, o objectivo do presente estudo é analisar a representação de reclusos que beneficiaram da formação de educação de pares sobre as principais implicações e desafios deste método de intervenção na promoção do seu desenvolvimento pessoal e social.

\section{Metodologia}

\subsection{Participantes}

A estratégia para a seleção da amostra é considerada intencional (PATTON, 1990), na medida em que foram selecionados para o estudo os participantes que beneficiaram da formação em educação de pares implementada no EPG. Ao longo das 3 edições (2010-2012 / 2014-2016 / 2016-2018), 25 de um total de 64 educadores de pares participaram no estudo. Nesse sentido, foram realizados 6 focus groups (FG) constituídos entre 3 a 5 elementos com idades entre 23 e 51 anos $(\mathrm{M}=33.2, \mathrm{DP}=8.1)$. Os focus groups foram realizados aquando do término de cada uma das formações (2 FG; 3 FG e 1 FG, respectivamente). Dado que estudo foi desenvolvido no setor masculino do EPG, os participantes são do sexo masculino. Por último, na seleção dos educadores de pares que participaram no focus group teve-se como critério: i) participação voluntária ii) conclusão da formação com sucesso, incluindo a parte prática (intervenção com os pares); iii) permanecer no Estabelecimento (não terem saído em liberdade, nem transferidos para outros Estabelecimentos); iv) terem disponibilidade (por motivos associados a dinâmicas do próprio Estabelecimento). Antes da realização do FG foi explicado o contexto e o propósito da realização do mesmo, assim como o seu caráter voluntário e anónimo e a forma como este iria ocorrer. A cada participante foi atribuído um número em cada FG, nunca tendo sido referido o nome de nenhum dos participantes ou outra característica identificativa. Os FG foram conduzidos por dois elementos da equipa: um 
observador e um entrevistador. As respostas dos participantes foram transcritas e subsequentemente procedeu-se à análise de conteúdo das mesmas. A análise de conteúdo implicou o acordo de 2 investigadores, resultando a formulação de categorias e subcategorias de um processo de análise conjunta.

\subsection{Instrumento e Procedimento}

Foi utilizada uma metodologia qualitativa de investigação visto ser considerado o método preferencial de análise em fases exploratórias da investigação e para a recolha de dados sobre fenómenos complexos tais como dimensões relacionais mais difíceis de apreender através de métodos quantitativos (Patton, 1990; Strauss \& Corbin, 1990). Dada a dimensão exploratória do estudo e o objetivo de fazer emergir dimensões para a problematização do papel do educador de pares no contexto prisional selecionou-se o focus group enquanto método de recolha de dados. O focus groups designa discussões de grupos em que se explora um conjunto específico de temas, sendo fundamentalmente uma forma de ouvir pessoas e aprender com elas (Nata, 2007).

A análise de conteúdo preconizada engloba 3 fases: i) fase de préexploração do material ou de leituras; ii) seleção das unidades de análise (ou unidades de significados); iii) processo de categorização e sub-categorização (Campos, 2004).

O guião do focus groups foi sofrendo pequenas alterações ao longo das edições, no entanto as questões core são transversais e centraram-se nas seguintes dimensões:

- Percepção das implicações da formação no comportamento do indivíduo (exploração da dimensão comportamental, cognitiva e emocional)

- Percepção do papel de educador de pares no estabelecimento prisional (implicações no comportamento do próprio ou do comportamento do outro, reclusos e agentes do EPG).

- Percepção de mudança atribuída ao processo de formação em educação de pares.

\section{Resultados e discussão de resultados}

Da realização dos focus groups surgiram quatro grandes categorias:

1) valorização do sentido de competência pessoal

2) reforço de competências sociais

3) aumento da capacidade de participação no espaço público

4) empoderamento do indivíduo. 
Na figura 1 encontra-se uma representação gráfica das categorias e subcategorias que emergiram no processo de análise de conteúdo. Cada uma destas dimensões será apresentada e discutida de seguida.

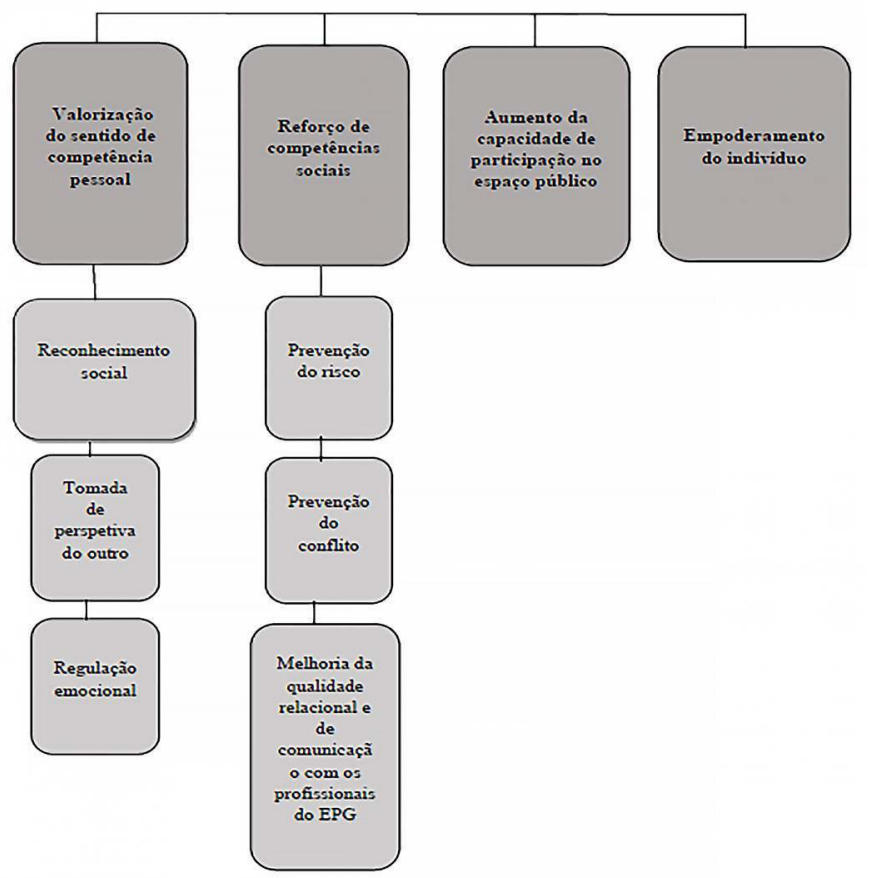

Figura 1. Categorias e subcategorias que emergiram no processo de análise de conteúdo

\section{Categoria 1: Valorização do sentido de competência pessoal}

A aquisição de ferramentas e instrumentos comunicacionais dos Educadores de Pares que lhes permitiram aumentar o conhecimento sobre si mesmo e facilitar a comunicação com o outro, parece ser considerada pelos participantes como momento optimal para uma imagem mais positiva de si e do seu potencial de ajuda. Esta valorização do sentido de competência pessoal operacionaliza-se em três grandes dimensões: (i) regulação emocional, (ii) tomada de perspectiva do outro e (iii) reconhecimento social. A formação foi percepcionada pelos participantes como sendo um instrumento relevante para a promoção do autoconhecimento, da autoestima, e no incremento de um sentido de competência pessoal na resolução de conflitos internos. Competência que também parece actualizar-se na percepção de competências sociais, nomeadamente na capacidade de ajuda ao outro. Para além disso, os educadores de pares consideraram que a formação os ajudou a diferenciar e regular as suas emoções 
nomeadamente no que se refere à ansiedade e à frustração, estando mais capacitados para fazer uma gestão de situações de crise.

Eu falo por mim tornou-me mais (...) mais calmo e mais, uma mente mais aberta (...) para certas ocasiões e para certos momentos, pronto, o que notei antes da formação sei lá se calhar pensava "quero é saber de mim e dormir, passar o dia aí, está tudo bem”, hoje, depois da formação não, penso sei lá, por exemplo antes da formação pensava não consigo dormir e não sei quê, se calhar vou pedir medicação mas agora hoje em dia penso "não, não vale a pena", (...) depois da formação tento explicar isso aos outros, o que está mal, também em certos comportamentos de alguns reclusos, de ir fazer barulho para o gradão a pedir essas coisas assim também não vão a lado nenhum, e digo isso também com a formação mais vale dirigir-me à pessoa indicada e falar frente a frente e expor o meu problema, expor o que é que se passou, porque estar a fazer barulho por nada isso só vai levar a mais conflito.

Ainda no que se refere a competências relacionais, as narrativas dos EP revelam que a formação teve um impacto benéfico num processo de tomada de perspetiva do outro, nomeadamente no que se refere aos problemas enunciados pelos seus pares.

Permitiu-me dar mais força à minha postura digamos assim, neste momento posso ser uma pessoa ainda mais neutra, mais equilibrada, com acesso a mais informação para passar aos outros, é introduzir a melhor mensagem possivel (...).

O exercício das funções de educadores de pares para além de contribuir para um processo de valorização interna de cada educador, levou também a um reconhecimento externo, por parte dos seus pares e dos próprios técnicos do EPG, com um reconhecimento social da sua posição de educadores de pares e da sua intervenção.

Eu penso que ao sermos Educadores de Pares as pessoas veem-nos com outros olhos, porque eles pensam "pronto eles têm aquela formação" $e$ especialmente, eu falo por mim, a formação ensinou-me também a lidar com certas situações. 


\section{Categoria 2: Reforço de competências sociais}

Foram sentidos como sendo particularmente incrementados no processo de educação de pares os recursos e competências sociais dos Educadores de Pares, quer pelo aumento de conhecimento, quer pela capacitação para tomadas de decisão e resolução de problemas de forma mais adaptativa. O reforço do sentido de competência social está patente na percepção de aumento de estratégias que contribuem para (i) prevenção do risco; (ii) prevenção do conflito; e (iii) melhoria da qualidade relacional e de comunicação com os profissionais do Estabelecimento Prisional.

"Os educadores de pares conseguem ir onde nenhum técnico vai”, tendo acesso a uma população "escondida", pois, para lá do "gradão" só entram os reclusos e os guardas. De facto, os educadores de pares estão onde acontecem as situações e os comportamentos de riscos, podendo atuar in loco e em tempo real. Desta forma, os educadores de pares assumiram uma posição privilegiada para identificar comportamentos de risco que de outro modo permaneceriam ocultos actuando como agentes chave para a promoção da saúde em contexto prisional.

As únicas pessoas que entram dentro dos pisos, para além de nós que lá estamos, são os guardas.

Nós contactamos diariamente praticamente com os pares, não é, e fazemos intervenções praticamente diárias e vamos acompanhando os casos e vamos sempre dando uma palavra, dando um conselho, dando apoio, de maneira a que as pessoas nos reconheçam e até se estabeleça alguma relação, que de outra forma não existia, acabamos por ser sempre um ponto de apoio para essas pessoas.

A perceção dos Educadores de Pares é que a sua intervenção desempenha um papel importante na pacificação das relações entre os reclusos, contribuindo para a prevenção de conflitos e para um ambiente mais calmo entre reclusos.

O facto é que já muitos problemas já foram evitados através das nossas intervenções, porque nota-se, por exemplo, a nivel do piso que as coisas estão relativamente calmas, que não existem, basicamente, não existem confusões, não existem assim grandes atritos, grandes problemas e eu penso que isso pode-se dever a conforme se vão resolvendo os problemas, mesmo que sejam pequenos, a pouco e pouco, eles depois não tomam aquela forma de bola de neve muito grande que depois já é muito difícil controlar e assim vai-se conseguindo equilibrar a situação para não tomar proporções muito grandes. 
A aquisição de novas formas de comunicação e o desenvolvimento de competências interpessoais por parte dos educadores teve um reflexo direto na melhoria da qualidade da relação e da comunicação não só com os seus pares, mas também com os profissionais do EPG, levando a um reforço relações interpessoais, especialmente, com os outros reclusos.

(...) houve certos temas tratados que nós lá dentro discutimos, há pessoas que entendem de uma maneira, há pessoas que entendem de outra $e$ é bom estarmos em grupo e discutir isso para chegarmos a um consenso e para abrir mais a mentalidade das pessoas, para elas pensarem de outra maneira.

A formação ensinou-me também a lidar com certas situações e a saber falar consoante certas situações.

\section{Categoria 3: Aumento da capacidade de participação no espaço público}

No que respeita à integração do papel do educador de pares, verificou-se que uma das dimensões mais enunciadas se associa com a auto-responsabilização dos Educadores de Pares pela participação no espaço público. Esta categoria operacionaliza-se na participação no planeamento e apoio à dinamização das ações de sensibilização, assim como a disponibilidade para contactar espontaneamente os restantes reclusos, trazendo os temas da promoção da saúde e da prevenção do consumo de substâncias psicoativas e comportamentos de risco.

Eu mesmo pessoalmente também consegui evoluir numa série de pontos, não é bem esta a minha área nem sequer de interesse até agora, mas no meio prisional acabou por fazer um bocado parte, digamos assim, é uma responsabilidade que me foi incutida, digamos que eu levei isto como se fosse um trabalho, uma ocupação, não é, em part-time digamos assim porque eu tenho outras mas de qualquer maneira acaba por ser uma responsabilidade, responsabiliza as pessoas que fazem parte, que fizeram parte desta formação e acho que é muito importante; nós somos os veículos dessa informação que tem de ser dada e deve ser dada às pessoas.

Posso falar por experiência própria, que nos tornamos uma referência dentro do piso, uma vez que ajudámos uma série de companheiros a ultrapassar uma série de dificuldades, conseguimos através da informação que nos foi fornecida ultrapassar uma série de mitos que com falta de informação correta muitas vezes atalhavam uns de uma maneira outros de outra e nós com acesso a essa informação e com essa 
documentação pudemos passar uma mensagem mais clara e mais assertiva sobre certos problemas que se podem tornar muito graves dentro de um meio fechado, como é o meio prisional.

Acho que olham para nós como pessoas crediveis, não é, que falam só quando têm informação correta, que nos pautamos por ser pessoas com o máximo de assertividade possivel, acho que nos tomam também como uma referência.

\section{Categoria 4: Empoderamento do indivíduo}

Esta categoria surge como corolário das categorias anteriormente enunciadas. A formação e posterior implementação de estratégias de Educação de Pares permitiu o acesso privilegiado a conhecimento e a momentos considerados optimais para a exploração de dimensões da vivência pessoal do recluso. Estes momentos foram significados como sendo fundamentais para o desenvolvimento de competências de tomada de decisão, de resolução de problemas, gestão de conflitos, de flexibilização, de assertividade e de tomada de perspetiva do outro. Esta metodologia permitiu uma melhoria da capacidade de comunicação, do relacionamento interpessoal e aumento da participação no espaço público por parte dos educadores. Todo este sentido de competência pessoal parece resultar no empoderamento do indivíduo. Algo que nos parece fundamental no processo de reinserção do indivíduo e na construção do seu projeto de vida. Verificando-se desta forma o potencial desta metodologia na promoção do desenvolvimento do sujeito e na projeção da sua imagem no futuro, ultrapassando, por isso, os "muros da prisão".

Eu acho que esta formação junto com outras e outros conhecimentos que eu tenho, quer eu queira quer não, mudou a minha vida, porque eu passo por um problema e não consigo evitar ir lá, mesmo que não vá resolver nada, vou ajudar. E lá fora, principalmente, aqui dentro, é neste momento que eu estou agora e é aqui onde eu tento ajudar, lá fora eu moro num bairro social e um bairro muito problemático, eu acho que eu vou, desde as pessoas com mais idade até à pouca idade, eu vou ajudar, naquilo que eu puder ajudar en vou ajudar.

\section{Considerações finais}

O objetivo do presente estudo foi contribuir para a problematização da educação de pares em contexto prisional. Nesse sentido foram apresentados os resultados da análise de 6 focus groups realizados no âmbito do Projecto Inclus@ implementado no EPG. Esta análise não procurou construir uma teoria sobre 
a educação de pares ou avaliar a eficácia desta metodologia de intervenção, mas chamar os reclusos a refletir e discutir sobre o processo de ser e tornar-se um educador de pares no contexto prisional no Estabelecimento Prisional da Guarda.

$\mathrm{Na}$ análise preconizada emergiram 4 categorias: (1) valorização do sentido de competência pessoal, (2) reforço de competências sociais, (3) aumento da capacidade de participação no espaço público e (4) empoderamento do indivíduo.

É um tema transversal às diferentes categorias enunciadas a diferenciação de um sentido progressivo de competência pessoal que surge da ressonância afetiva que a experiência de utilidade e de apoio ao outro lhes devolve. Tal poderá revelar-se um fator mediador importante entre a experiência de reclusão e o risco extensamente reportado pela investigação no que se refere à saúde, ao estigma e à marginalização social. Segundo uma metanálise publicada em 2015 que envolveu a revisão sistemática de 57 estudos no âmbito da eficácia da educação de pares nas prisões, alguns dos benefícios desta estratégia de intervenção referem-se à prevenção de comportamentos de risco e à promoção da saúde mental (BAGNALL, 2015).

Foi também interessante verificar que algumas das pessoas mencionaram a intenção de continuarem enquanto Educadores de Pares fora do espaço prisional. Este dado alerta-nos para a possibilidade desta intervenção se projetar no tempo e se constituir enquanto momento optimal para promover mudanças estruturais no sujeito, nomeadamente na forma como se significa e se define.

\section{Ajudou-me a construir digamos uma imagem mais sólida, como refe- rência entre os pares e pessoalmente em certos pontos, a nivel de comu- nicação, a nível de certos pormenores de entrosamento mesmo com os companheiros, ajudou-me bastante.}

É interessante verificar que a educação de pares pode constituir-se como instrumento poderoso para que a pessoa se experimente e reinvente no espaço da prisão e para que a experiência de reclusão seja significada também enquanto promotora do conhecimento de si mesmo. Pensamos que isto por si só revelar-se-á fundamental para que o indivíduo desenvolva uma abordagem mais compreensiva de si mesmo, das suas circunstâncias e do mundo.

Ao longo das edições do projecto Inclus@ foram identificadas diferentes mais valias na integração de educadores de pares na intervenção desenvolvida com reclusos no EPG, nomeadamente no que se refere ao acesso privilegiado a pessoas que não procuram ajuda nas respostas formais pré-existentes, o desenvolvimento de respostas em tempo real, como sendo a resolução de conflitos, adopção de comportamentos de menor risco e o apoio emocional (APDES, 2016). A Educação de Pares pode ser assim considerada um importante 
mecanismo para incrementar as condições de bem-estar na prisão, com resultados positivos observados quer nos educadores quer nos pares (Bagnall, 2015).

\section{Limitações e implicações do estudo}

As limitações do estudo prendem-se com o tipo de metodologia utilizada e com o espaço específico de intervenção em análise. A metodologia qualitativa não permite a generalização dos resultados a outros contextos ou indivíduos. A utilização sequencial de uma metodologia quantitativa poderia ajudar a compreender em que medida os dados se podem actualizar noutros contextos de reclusão.

Sabendo que a instância prisional se reveste de diversos condicionalismos atendendo aos mecanismos de controlo que se exigem, os dados recolhidos no âmbito do presente estudo foram realizados também pela pessoa responsável pela intervenção. Se, por um lado, foi investida uma relação de confiança com as pessoas em situação de reclusão, por outro lado, tal poderá levantar questões de desejabilidade social. O desejável seria que o investigador e os interventores desempenhassem papéis diferenciados.

A permanente alteração do contexto interventivo, devido ao fluxo de entradas e saídas de reclusos, que resultam de transferências de e para outros estabelecimentos prisionais, de saídas em liberdade e da entrada de novos reclusos, constituiu também um desafio acrescido à intervenção e à investigação. Adicionalmente, o processo de seleção dos educadores de pares foi efetuado num contexto que por si só apresenta algumas limitações e dificuldades específicas, quando comparado com contextos onde não se verifica a privação de liberdade. Assim, foram consideradas novas variáveis na seleção dos Educadores de Pares, para além daquelas que inicialmente se preconizavam como as mais adequadas para o desenvolvimento de funções de um Educador de Pares, como a pré-seleção efetuada pelos técnicos do EPG, os condicionalismos das medidas de segurança e as rotinas quotidianas, principalmente no que respeita às atividades escolares e laborais. Este processo acabou por ser condicionado, visto que para além da seleção ter sido efetuada através dos critérios definidores de um perfil adequado a um educador de pares, também se teve em conta as dinâmicas quotidianas existentes no EPG.

Em estudos futuros seria importante aprofundar a eficácia desta metodologia enquanto estratégia de intervenção e avaliar o seu impacto quer na população reclusa, quer nos educadores de pares e demais profissionais envolvidos no processo de Educação de Pares, estendendo o estudo a outros Estabelecimentos Prisionais em Portugal. Nesse sentido seria necessário recorrer a desenhos metodológicos mais complexos como sendo os quasi-experimentais, que preconizam a existência de métodos de recolha pré e pós intervenção e grupos de intervenção e de controlo. Adicionalmente a triangulação de informação 
de outros actores chave do contexto prisional como sendo os pares, guardas prisionais, técnicos e direcção poderá constituir-se uma mais valia relevante no desenho de intervenções futuras que integrassem esta metodologia na intervenção com a comunidade prisional. Uma avaliação de custo-eficácia seria fundamental se considerarmos a hipótese de estender a implementação desta metodologia a outros contextos prisionais do país.

\section{Referências bibliográficas}

APDES (2012), Manual o Trabalho primeiro, (s/l), APDES, Disponível em https://comum.rcaap. $\mathrm{pt} / \mathrm{handle} / 10400.26 / 4223$.

APDES (2016), Manual para a Educação de Pares em contexto prisional, (s/l), APDES.

BAGNALL, Anne-Marie, et. al, (2015), "A systematic review of the effectiveness and cost-effectiveness of peer education and peer support in prisons", BMC Public Health, 15:290, doi:10.1186/s12889-015-1584-x, disponível em: https://bmcpublichealth.biomedcentral. com/articles/10.1186/s12889-015-1584-x, [consultado em 25-05-2017].

BARRY, J. B. et al. (2010), "Primary medical care in Irish prisons", BMC Health Service, 10(74), disponível em: http://www.biomedcentral.com/1472-6963/10/74/, [consultado em 25-05-2017].

CARVALHO, Cláudia (2003), Corpos Minados - um estudo exploratório no espaço interno da cultura prisional, CES, FEUC.

CRI (2017), Estabelecimento Prisional da Guarda - Atualização do diagnóstico 2016/2017, disponível em http://www.sicad.pt/BK/Concursos_v2/Documents/2017/EPG_Actual_ Diagnostico.pdf [consultado em 25-01-2018].

CONSELHO DA UNIÃO EUROPEIA (2008), "Plano de Acção da UE em matéria de Luta contra a Droga (2009-2012)”, Jornal Oficial da União Europeia, C326/7-C326/25, disponível em: http://www.sicad.pt/BK/Publicacoes/Lists/SICAD_PUBLICACOES/Attachments/54/ PAUE2012-PT.pdf, [consultado em 25-05-2017].

CUNHA, Anabela R. G. (2013), Práticas educativas em contexto prisional, Instituto da Educação, disponível em https://www.google.com/url?q=http://repositorio.ul.pt/bitstream/10451/10236/1/ulfpie044887_tm.pdf\&sa=D\&ust=1517398365272000\&usg=AFQjC NGGT1Y_tFeSRTJCOtZpRVKj8xdPXQ, [consultado em 25-05-2017].

CUNHA, Manuela I. (2008), Aquém e além da Prisão. Cruzamentos e Perspectivas, Lisboa: 90 Graus.

DEVILlY, G. J.; SORBELLO, L.; ECCLESTON, L.; WARD, T. (2005), "Prison-based peer-education schemes", Aggression and Violent Behavior, 10, 219-240.

DUMONT, D. M., BROCKMANN, B., DICKMAN, S., ALEXANDER, N., \& RICH, J. D. (2012), "Public Health and the Epidemic of Incarceration", Annual Review of Public Health, 33, 325-339, http://doi.org/10.1146/annurev-publhealth-031811-124614, disponível em: https://www.ncbi.nlm.nih.gov/pmc/articles/PMC3329888/, [consultado em 25-05-2017].

EMCDDA (2012), Prisons and drugs in Europe: The problem and responses, Lisboa, OEDT, disponível em: http://www.emcdda.europa.eu/attachements.cfm/att_191812_EN_ TDSI12002ENC.pdf, [consultado em 24-05-2017].

FAZEL S.; DANESH, J. (2002), "Serious mental disorder in 23000 prisoners: a systematic review of 62 surveys”, Lancet 2002 Feb 16; 359(9306):545-50, disponível em: http://www.antoniocasella.eu/archipsy/Fazel_Danesh_16feb2002.pdf, [consultado em 25-05-2017]. 
FOUCAULT, Michel (1999), Vigiar e Punir: nascimento da prisão, tradução de Raquel Ramalhete, 20. ${ }^{a}$ ed. Petrópolis, Editora Vozes.

GOMES, Sílvia (2014), Caminhos para a prisão - Uma análise do fenómeno da criminalidade associada a grupos estrangeiros e étnicos em Portugal, V. N. Famalicão, Edições Húmus.

GOMES, Sílvia; SILVA, Manuel Carlos (2014), “Condições e trajetórias de vida de reclusos e reclusas de etnia cigana...", Sociologia, Revista da Faculdade de Letras da Universidade do Porto, Número temático - Ciganos na Península Ibérica e Brasil: estudos e políticas sociais, 77-95, disponível em: http://ler.letras.up.pt/uploads/ficheiros/12945.pdf, [consultado em 24-05-2017].

GOFFMAN, Erving (1961), Manicômios, Prisões e Conventos, tradução de Dante Moreira Leite. São Paulo: Editora Perspectiva.

HATZENBUEHLER, M. L.; PHELAN, J. C., \& LINK, B. G. (2013), "Stigma as a fundamental cause of population health inequalities", American Journal of Public Health, 103(5), 813821, doi:10.2105/ajph.2012.301069, disponível em: https://www.ncbi.nlm.nih.gov/pmc/articles/PMC3682466/, [consultado em 25-05-2017].

HOLMES, C. C. (2002), Crime and poverty, disponível em: www.pubdef.ocgov.com/poverty. html, [consultado em 25-05-2017].

NATA, G. (2007), Diferença Cultural e Democracia. Identidade, Cidadania e Tolerância na Relação entre Maioria e Minorias, Dissertação de doutoramento, Faculdade de Psicologia e de Ciências da Educação da Universidade do Porto, Porto.

NISA, A.; CARVALHO, H.; CASTRO, D.; TRINDADE, S.; LAMEIRA, C. (2016), "A educação de pares em contexto prisional: Rebatendo Estigmas", $11 .{ }^{\circ}$ Congresso Nacional de Psicologia da Saúde, ISCTE-IUL, Lisboa.

OBSERVATÓRIO PORTUGUÊS DE SISTEMAS DE SAÚDE (s/d), Saúde nas prisões portuguesas, disponível em: http://www.opss.pt/sites/opss.pt/files/saude+nas+prisoes+portuguesas. pdf, [consultado em 24-05-2017].

PATTON, M. Q. (1990), Qualitative evaluation and research methods (2nd ed.), Newbury Park, CA, Sage Publications.

RASI (2016), Relatório de Anual de Segurança Interna, Sistema de Segurança Interna, Portugal.

SICAD (2013), Plano Nacional para a Redução dos Comportamentos Aditivose das Dependências 2013-2020, Lisboa, SICAD, disponível em: http://www.sicad.pt/BK/Institucional/ Coordenacao/Documents/Planos/SICAD_Plano_Nacional_Reducao_CAD_2013-2020.pdf [consultado em 25-05-2017].

SICAD, Relatório Anual 2015 - A situação do país em matéria de drogas e toxicodependências, 2016 (http://www.sicad.pt/BK/Publicacoes/Lists/SICAD_PUBLICACOES/Attachments/114/ Relatório\%20Anual\%20Drogas\%20e\%20Toxicodependências\%202015.pdf).

SILVA, Manuel Carlos (2009), "Desigualdades e exclusão social: De breve revisitação a uma síntese proteórica”, Configurações (5/6), 11-40, disponível em: http://repositorium.sdum.uminho.pt/bitstream/1822/37462/1/Configuracoes\%205-6.pdf, [consultado em 25-05-2017].

SISTEMA DE SEGURANÇA INTERNA (2015), Relatório Anual de Segurança Interna (RASI, 2014), disponível em: http://www.portugal.gov.pt/media/6877606/20150331-rasi-2014.pdf, [consultado em 25-05-2017].

SISTEMA DE SEGURANÇA INTERNA (2017), Relatório Anual de Segurança Interna (RASI, 2016), disponível em: http://www.portugal.gov.pt/media/26816790/20170331-pm-rasi.pdf, [consultado em 24-05-2017].

STOVER, H.; WEILANDT, C. (2007), "Drug use and drug services in prisons”, In MOLLER, L. et al, (2007) (Eds.). Health in Prisons - A WHO guide to the essentials in prison health, World Health Organization, disponível em: http://www.euro.who.int/__data/assets/pdf_ file/0009/99018/E90174.pdf, [consultado em 25-05-2017], 100-101. 
STRAUSS, A., \& CORBIN, J. (1990), Basics of qualitative research: Grounded theory procedures and techniques, Newbury Park, California, Sage Publications.

TORRES, Anália (INCAMP, 2014), Inquérito Nacional sobre Comportamentos Aditivos em Meio Prisional (INCAMP), $3^{\mathrm{a} e d}$., disponível em: http://www.sicad.pt/BK/Lists/SICAD_ NOVIDADES/Attachments/66/Sumário\%20executivo_INCADMP.pdf, [consultado em 24-05-2017].

TORRES, Anália (INCAMP, 2016), Inquérito Nacional sobre Comportamentos Aditivos em Meio Prisional, Caracterização da população prisional, crimes cometidos e dependências face às drogas, bebidas alcoólicas e jogo a dinheiro, disponível em: http://www.sicad.pt/ BK/EstatisticaInvestigacao/EstudosConcluidos/Lists/SICAD_ESTUDOS/Attachments/158/ INCAMP_2016_Volume1.pdf, [consultado em 24-05-2017].

WACQUANT, Loïc (2009), “O estigma racial na construção do Estado punitivo americano", Configurações (5/6), 41-54, disponível em: http://repositorium.sdum.uminho.pt/bitstream/1822/37462/1/Configuracoes\%205-6.pdf, [consultado em 25-05-2017].

WHO (2007a), Health in prisons, A WHO guide to the essentials in prison health, Copenhaga: WHO Europe, disponível em: http://www.euro.who.int/__data/assets/pdf_file/0009/99018/ E90174.pdf, [consultado em 24-05-2017].

WHO (2007b), Effectiveness of interventions to address HIV in prisons, http://www.who.int/hiv/ idu/OMS_E4Acomprehensive_WEB.pdf, consultado em [24-05-2017].

UNAIDS (2014), THE GAP REPORT 2014, disponível em: http://www.unaids.org/sites/default/ files/media_asset/03_Prisoners.pdf, [consultado em 24-05-2017].

UNODC (2008), HIV and AIDS in places of detention. A toolkit for policymakers, programme managers, prison officers and health careproviders in prison settings, Nova Iorque: UN, disponível em: https://www.unodc.org/documents/balticstates//Library/PrisonSettings/PrisonToolkit/ HIVAIDS_in_places_of_detention_Toolkit_EN.pdf, [consultado em 24-05-2017].

\section{Nota}

Este artigo foi elaborado com elementos recolhidos no âmbito da intervenção no EPG e presentes em Relatórios finais enviados ao SICAD.

\section{Agradecimentos}

Não podemos deixar de expressar o nosso agradecimento aos reclusos que ao longo destas três edições integraram o grupo de Educadores de Pares da APDES no EPG, em especial aos que participaram no presente estudo. Agradecemos também aos companheiros/as da APDES que têm colaborado e emprestado o seu saber ao Projeto. Por último, queremos deixar um agradecimento muito especial ao Diretor do Estabelecimento Prisional da Guarda, Dr. Luís Couto, a toda a Direção, Equipa Técnica e Guardas do EPG, assim como ao Diretor e a todos/ as técnicos/as do CRI da Guarda, pelos anos de colaboração e de cumplicidade com o trabalho desenvolvido no âmbito do projecto Inclus@. Obrigado a tod@s!

\section{Financiamentos}

Este Projeto é co-financiado pelo SICAD e pela FCT - Fundação para a Ciência e Tecnologia. 